(c) American Dairy Science Association, 2005.

\title{
Comparison of the Functionality of Exopolysaccharides Produced In Situ or Added as Bioingredients on Yogurt Properties
}

\author{
Y. Doleyres, L. Schaub, and C. Lacroix \\ Laboratory of Food Biotechnology, Institute of Food Science and Nutrition, Swiss Federal Institute of Technology, \\ Schmelzbergstrasse 7, 8092 Zurich, Switzerland
}

\begin{abstract}
The effect on yogurt properties of in situ production of exopolysaccharides (EPS) and addition of 2 EPS powders (crude and purified EPS from Lactobacillus rhamnosus RW-9595M fermentation in whey-based medium) at different concentrations was studied. No effect of purified powder addition for EPS concentrations up to $500 \mathrm{mg} / \mathrm{L}$ was observed on acidification rate to the difference of milks supplemented with crude EPS, which exhibited longer acidification times. The addition of EPS from 125 to $500 \mathrm{mg} / \mathrm{L}$ or the use of EPS-producing cultures resulted in yogurts with lower yield stress and viscoelastic moduli compared with control yogurts without EPS, with no apparent effect of EPS concentration. However, the consistency index was higher for yogurts produced with the commercial EPS-producing culture, and to a lesser extent with the mixed culture containing Lb. rhamnosus RW-9595M, compared with yogurts supplemented with EPS powders, which were not different from that for control yogurts. Our study showed that the mode of EPS incorporation in yogurts has a major effect on the rheological properties of the final product. (Key words: yogurt, exopolysaccharide, bioingredient, rheology)
\end{abstract}

Abbreviation key: C- = crude EPS powder, D- = EPSproducing starter culture (DI-PROX TY 975), EPS = exopolysaccharides, $\mathbf{G}^{\prime}$ and $\mathbf{G}^{\prime \prime}=$ elastic and viscous moduli, respectively, $\mathbf{L R}=$ yogurt made with Lactobacillus rhamnosus RW-9595M, P- = purified EPS powder, V- = EPS-nonproducing starter culture (Visbyvac B500), WHC = water-holding capacity.

\section{INTRODUCTION}

Several lactic acid bacteria are known to produce polysaccharides that are excreted into the environment. These polysaccharides called exopolysaccharides (EPS)

Received June 2, 2005.

Accepted August 11, 2005.

Corresponding author: Christophe Lacroix; e-mail: christophe. lacroix@ilw.agrl.ethz.ch. are described as "mucoid" or "ropy" depending on whether they are attached to the bacterial cells as capsules or found as unattached material in the surrounding medium (Sutherland, 1972).

The EPS-producing lactic acid bacteria have been traditionally used in Scandinavia to produce ropy sour milks (Wacher-Rodarte et al., 1993). On the other hand, in situ production of ropy EPS plays an important role in the manufacture of a variety of cultured dairy products such as yogurt, drinking yogurt, cheese, cultured cream, and milk-based desserts. Although produced at low levels (25 to $600 \mathrm{mg} / \mathrm{L}$; Cerning, 1995), they contribute to the texture, mouthfeel, taste perception, and stability of the final products. Acting as texturizing and stabilizing agents, EPS decrease syneresis and improve product stability (De Vuyst and Degeest, 1999b). Moreover, some EPS classified as prebiotics could contribute to human health and positively affect the gut microflora (Ruas-Madiedo et al., 2002a). It is also speculated that the increased viscosity of EPS-containing foods increases the residence time of ingested fermented milk in the gastrointestinal tract and might, therefore, be beneficial to a transient colonization by probiotic bacteria. Furthermore, EPS can contribute to human health due to their antitumor, antiulcer, immunomodulating, or cholesterol-lowering activities (Ruas-Madiedo et al., 2002a).

Difference of texture among yogurts containing EPS is rarely linked to differences in EPS concentrations, but more often to EPS intrinsic viscosity, which depends on molecular mass and stiffness (Faber et al., 1998; Kleerebezem et al., 1999). Moreover, EPS localization within the gel is also an important factor influencing the viscosity (Sodini et al., 2004). It has been shown that attractive interactions, commonly referred to as depletion interactions, are induced between aggregated whey protein colloid particles or between casein micelles when they are mixed with EPS (Tuinier et al., 1999a, 2000). The effects of EPS on the rheological properties and the microstructure of yogurt can thus be explained to a large extent by incompatibility with the milk protein aggregates, which was recently observed in yogurt using confocal scanning laser microscopy (Hassan et al., 2003). 
In spite of their interesting functional properties, EPS from lactic acid bacteria have not yet been exploited by food manufacturers as food additives, mainly because of low production levels compared with dextran-producing or gram-negative EPS-producing strains (De Vuyst and Degeest, 1999a). However, adding EPS powder as a bioingredient in milk before acidification by the lactic starter or after production; for example, at the same time as fruit/sugar/conservative adjunct, might be an interesting alternative to using EPS-producing strains. Therefore, this approach might be used to better control the rheological characteristics of fermented milks and avoid the serious problems of genetic instability of EPS production (Duboc and Mollet, 2001). For this, the development of a procedure for high EPS production and purification under optimized conditions is required for large-scale applications, as well as the use of a high EPS-producing strain with characteristics and functionalities that are compatible with use in milk products.

In a previous study, a very high EPS concentration of $2.3 \mathrm{~g} / \mathrm{L}$ was obtained during $\mathrm{pH}$-controlled batch cultures of Lactobacillus rhamnosus RW-9595M in $8 \%$ whey permeate medium supplemented with $\mathrm{MgSO}_{4} \cdot 7 \mathrm{H}_{2} \mathrm{O}, \mathrm{MnSO}_{4} \cdot \mathrm{H}_{2} \mathrm{O}$, Tween 80 , and yeast extract for final concentrations of $0.5 \mathrm{~g} / \mathrm{L}, 0.05 \mathrm{~g} / \mathrm{L}, 1 \mathrm{~mL} /$ $\mathrm{L}$, and $10 \mathrm{~g} / \mathrm{L}$, respectively (Bergmaier et al., 2003). Moreover, the EPS produced by $L b$. rhamnosus RW$9595 \mathrm{M}$ was thought to exhibit interesting properties for stabilizing acidified milk products because of low charge density (Van Calsteren et al., 2002), and exhibited in vitro immunomodulating properties on human and mouse cultured immunocompetent cells (Chabot et al., 2001).

The objective of this study was to determine the effects of EPS addition on acidification time, and syneresis, postacidification, and rheological properties of yogurts (13 and $14.2 \%$ milk solids) during 4 -wk storage at refrigeration temperature. Two powders with different EPS purities (dried crude fermented whey-based medium and EPS concentrated by ultrafiltration) were tested on yogurt properties and compared with EPS produced in situ by Lb. rhamnosus RW-9595M added to the EPS-nonproducing starter culture, or by a commercial EPS-producing yogurt starter culture.

\section{MATERIALS AND METHODS}

\section{Cultures}

Lactobacillus rhamnosus RW-9595M was used as EPS-producer culture (Dupont et al., 2000; Macedo et al., 2002; Bergmaier et al., 2003). A stock culture was kept frozen in $12 \%$ (wt/vol) skim milk and $20 \%$ (wt/vol) glycerol at $-80^{\circ} \mathrm{C}$. For inoculum preparation, $1 \%$ of the frozen $L b$. rhamnosus RW-9595M was propagated in de Man, Rogosa, Sharpe (de Man et al., 1960) medium (Biolife, Milano, Italy) at $37^{\circ} \mathrm{C}$ for $18 \mathrm{~h}$.

For yogurt production, 2 commercial mixed cultures were used: a standard nonEPS yogurt culture (Yogurt 709 Visbyvac B 500, Danisco, Copenhagen, Denmark) and a commercial EPS culture (Bioprox DI-PROX TY 975, Protex International Group, Paris, France).

\section{EPS Batch Fermentation}

Batch fermentation was carried out in a 15-L bioreactor (NLF-19, Bioengineering AG, Wald, Switzerland) to produce sufficient amounts of EPS for the following experiments. Whey powder (Emmi, Dagmersellen, Switzerland) reconstituted at $11 \%$ solids was sterilized in situ for $15 \mathrm{~min}$ at $121^{\circ} \mathrm{C}$ and centrifuged batchwise at $8000 \times g$ for $10 \mathrm{~min}$ to remove the heat-formed precipitate. The supernatant was added to the bioreactor and supplemented with $\mathrm{MgSO}_{4} \cdot 7 \mathrm{H}_{2} \mathrm{O}, \mathrm{MnSO}_{4} \cdot \mathrm{H}_{2} \mathrm{O}$, and Tween 80 for final concentrations of $0.5 \mathrm{~g} / \mathrm{L}, 0.05 \mathrm{~g} / \mathrm{L}$, and $1 \mathrm{~mL} / \mathrm{L}$, respectively (Bergmaier et al., 2003). After a second sterilization for $15 \mathrm{~min}$ at $121^{\circ} \mathrm{C}, 28 \%$ (wt/ vol) sterile yeast extract was added to the whey-based medium for a final concentration of $1 \%$ (wt/vol). The fermentation ( $1 \%$ inoculum) was carried out for $48 \mathrm{~h}$ at $37^{\circ} \mathrm{C}$, with pH controlled at 6.0 with $5 \mathrm{M} \mathrm{NaOH}$, and mixing set at $400 \mathrm{rpm}$, because EPS production by $L b$. rhamnosus RW-9595M is only partially related to cell growth (Bergmaier et al., 2003). After fermentation, the medium was heated at $100^{\circ} \mathrm{C}$ for $10 \mathrm{~min}$ for cell and enzyme deactivation, and 2 samples were analyzed for EPS content using ultrafiltration cells and the phenol-sulfuric acid method, as well as for content in lactose, glucose, galactose, lactate, and acetate using HPLC.

\section{Production of EPS Powders}

Two types of EPS powders were produced. A "crude" EPS powder was obtained by freeze-drying (Genesis 25 EL, Virtis, Gardiner, NY) $5 \mathrm{~L}$ of the fermented medium for $3 \mathrm{~d}\left(3 \mathrm{~h}\right.$ at $-30^{\circ} \mathrm{C}$ and $30 \mathrm{~Pa}$ followed by $2 \mathrm{~h}$ at $-10^{\circ} \mathrm{C}$ and $10 \mathrm{~Pa}, 10 \mathrm{~h}$ at $20^{\circ} \mathrm{C}$ and $10 \mathrm{~Pa}$, and finally $57 \mathrm{~h}$ at $30^{\circ} \mathrm{C}$ and $10 \mathrm{~Pa}$ ) immediately after fermentation. To obtain a "purified" EPS powder, $6 \mathrm{~L}$ of the fermented medium was ultrafiltered before freeze-drying. After filling the reservoir with the medium at $30^{\circ} \mathrm{C}$, the pump was set at $3500 \mathrm{rpm}$ for medium recirculation through the external loop of the ultrafiltration device (Skanette, Skan AG, Allschwil, Switzerland). Ultrafiltration was performed with a $50-\mathrm{kDa}$ molecular weight cut-off membrane (Omega, Pall Corporation, Ann Arbor, MI). Compressed air at $10^{5} \mathrm{~Pa}$ was used to provide the driv- 
ing force until a concentration factor of 1.5 was reached. The concentrated EPS solution was then freeze-dried as described for the crude EPS powder.

Samples of the 2 types of powder were rehydrated in distilled water to determine the content of lactose, glucose, galactose, lactate, acetate, protein, and ash in EPS.

\section{EPS Quantification}

For EPS quantification in samples, EPS were partially purified using an ultrafiltration method as previously described by Bergmaier et al. (2001). A phenolsulphuric acid method (Dubois et al., 1956) was used to determine total sugar concentrations in retentate samples from ultrafiltration. Briefly, $200 \mu \mathrm{L}$ of filtrate or diluted retentate samples was mixed with $200 \mu \mathrm{L}$ of $5 \%$ phenol. Then, after addition of $1 \mathrm{~mL}$ of concentrated sulfuric acid, tubes were allowed to stand for $10 \mathrm{~min}$ at room temperature, followed by $15 \mathrm{~s}$ of vortexing. After another $20 \mathrm{~min}$, absorbance was measured at 490 $\mathrm{nm}$ with a spectrometer (Uvikon $810 \mathrm{P}$, Kontron, Zurich, Switzerland). Sugar concentration in samples was quantified using a standard curve with glucose ( 0 to $100 \mathrm{mg} / \mathrm{L})$. Reported data are means for duplicate ultrafiltrations and quantifications.

\section{HPLC Analyses}

Lactose, glucose, galactose, lactate, and acetate concentrations of samples from EPS batch fermentation and rehydrated crude and purified EPS powders were determined by HPLC (LaChrom HPLC system, Merck, Dietikon, Switzerland) using an Aminex HPX-87H ion exclusion column (Biorad, Rheinach, Switzerland) and $10 \mathrm{mM} \mathrm{H} \mathrm{SO}_{4}$ as eluent at a flow rate of $0.4 \mathrm{~mL} / \mathrm{min}$. For this, samples were centrifuged at $10,000 \times g$ for 10 min. Then, supernatants were diluted with nanopure water, filtered with a $0.45-\mu \mathrm{m}$ nylon-filter (Titan HPLC Filter, Infochroma, Zug, Switzerland), and placed in vials for HPLC analysis. Reported data are means for duplicate samples and analyses.

\section{Protein and Ash Analyses}

Crude protein content was determined in triplicate using the Kjeldahl method (method 955.04; AOAC, 1990), with a conversion factor from nitrogen to protein of 6.25. The ash content of the EPS powders was analyzed following method 942.05 of the AOAC (1990). Reported values are means and standard deviations for four experiments.

\section{Manufacture of Yogurts}

Different yogurt formulations were prepared by reconstituting in distilled water, milk powder containing $26 \%$ fat, $26 \%$ protein, $38 \%$ lactose, and $6 \%$ minerals (Emmi), supplemented with a milk protein concentrate powder containing $1 \%$ fat, $51 \%$ protein, $38 \%$ lactose, and 6\% minerals (Emmi), and crude or purified EPS powders (Table 1). Yogurt treatments are identified by a code comprising type of starter (V-; Visbyvac B 500, EPS-nonproducing culture; and D-; DI-PROX TY 975, EPS-producing culture), amount (125, 250, or $500 \mathrm{mg} /$ $\mathrm{L}$ of EPS), and type of EPS powder (P-; purified powder, C-; crude powder) or corresponding EPS producer (LR; Lb. rhamnosus), and last milk solid concentration level (13 or $14.2 \%)$.

Two different milk formulations were selected to compare the effect of fortified milk ( $14.2 \%$ milk) on yogurt characteristics with $13 \%$ milk, for different concentrations of EPS. After pasteurization at $90^{\circ} \mathrm{C}$ for $30 \mathrm{~min}$, $500 \mathrm{~mL}$ of the milk formulations were poured into Erlenmeyer flasks and transferred to a water bath. When temperature was stabilized at $41 \pm 1^{\circ} \mathrm{C}$, milks were inoculated with $1 \mathrm{~mL} / \mathrm{L}$ of yogurt starter culture and stirred.

For inoculum preparation, $4 \mathrm{~g}$ of EPS-nonproducing yogurt culture (Yogurt 709 Visbyvac B 500) or $8.6 \mathrm{~g}$ of EPS-producing yogurt culture (Bioprox DI-PROX TY 975) were rehydrated in $100 \mathrm{~mL}$ of $0.9 \% \mathrm{NaCl}$ solution and stored at $5^{\circ} \mathrm{C}$ until use, for a maximum of $48 \mathrm{~h}$. The production of yogurt V-500PF-14.2 was different from the other conditions, because the EPS powder was added only after yogurt production, but before cooling to $5^{\circ} \mathrm{C}$ for storage (Table 1 ). For the production of yogurt V-LR-13, 13\% milks were inoculated both by the EPSnonproducing yogurt culture and by an overnight culture of $L b$. rhamnosus RW-9595M in de Man, Rogosa, and Sharpe medium, using a $1.5 \%$ inoculum.

The $\mathrm{pH}$ values were automatically recorded every minute during milk acidification at $41^{\circ} \mathrm{C}$ without stirring using a Cinac system (Ysebeart, Frépillon, France). When $\mathrm{pH} 4.5$ was reached, the acidification was stopped by transferring the Erlenmeyer flasks to ice water. The yogurts were stirred with a magnetic bar at $300 \mathrm{rpm}$ for $1 \mathrm{~min}$ and supplemented with $5 \mathrm{~mL} / \mathrm{L}$ preservative agent ( $1 \%$ solution of potassium sorbate) to prevent growth of molds and yeasts during refrigerated storage. Then, the stirred yogurts were placed into plastic cups (100 mL each) and stored at $5^{\circ} \mathrm{C}$ for up to $4 \mathrm{wk}$. Yogurt productions were repeated twice.

\section{Water-Holding Capacity and Postacidification}

The water-holding capacity (WHC) of yogurts stored at $5^{\circ} \mathrm{C}$ for $1 \mathrm{~d}$, and after $1,2,3$, and 4 wk was determined 
Table 1. Conditions for yogurt production used in this study and mean acidification times to $\mathrm{pH} 4.5$ from duplicate experiments.

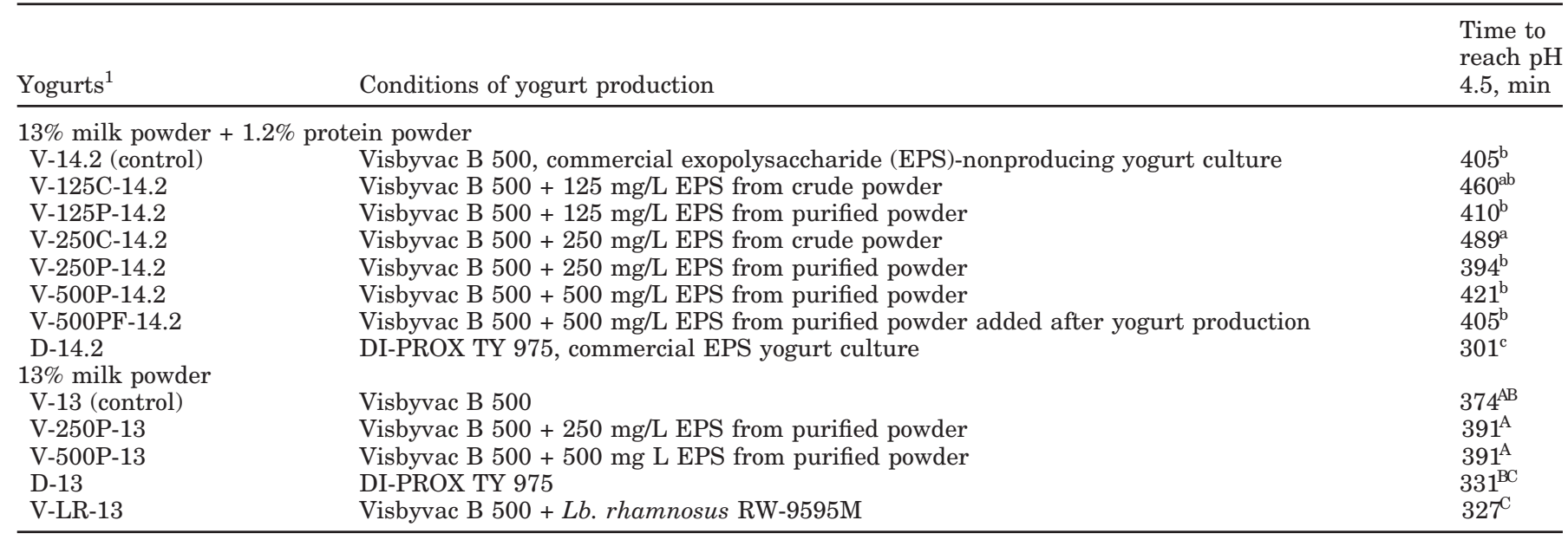

a,b,c,A,B,C Mean data with the same superscript letter are not significantly different $(P>0.05)$. Yogurts with 14.2 and $13 \%$ milk solids were produced in duplicate in 2 sets of experiments and analyzed separately (lowercase and uppercase letters, respectively).

${ }^{1}$ Yogurt treatments are identified by: type of starter (V = Visbyvac B 500, D = DI-PROX TY 975), amount (in mg), and type of EPS powder ( $\mathrm{P}=$ purified powder, $\mathrm{C}=$ crude powder) or corresponding EPS producer ( $\mathrm{LR}=$ Lb. rhamnosus), and last milk solid concentration level (13 or $14.2 \%)$.

as described by Cayot et al. (2003), with some modifications. Briefly, $10 \mathrm{~g}$ of yogurt was centrifuged at $5000 \times$ $g$ for $10 \mathrm{~min}$ at $5^{\circ} \mathrm{C}$. The resulting supernatant was carefully weighed to determine the amount of excluded water (\% wt/wt). Measurements of $\mathrm{pH}$ at $5^{\circ} \mathrm{C}$ were also carried out at the same storage times to determine postacidification due to the residual activity of the yogurt starter cultures at refrigerated temperature. Reported data are means for duplicate yogurt productions and analyses.

\section{Rheological Analyses}

The rheological properties of viscoelastic yogurts were determined in shear and dynamic modes using a Rheometer Paar Physica MCR300 (Anton Paar, Ashland, VA) fitted with a Couette measuring geometry (17 mm diameter). Measurements in both modes were carried out at $5^{\circ} \mathrm{C}$, with samples gently stirred 10 times by spoon before rheological analysis.

The shear rate was varied from 0.001 to $100 \mathrm{~s}^{-1}$ and the shear stress and apparent viscosity were recorded at increasing shear rates (upward flow curve) followed by decreasing shear rates (downward flow curve). The Herschel-Bulkley model for non-Newtonian fluids with a yield stress was used to fit the upward flow curves using the nonlinear regression tool from SPSS 11.0 (SPSS Inc., Chicago, IL):

$$
\tau=\tau_{0}+K \cdot \gamma^{\mathrm{n}},
$$

where $\tau=$ shear stress $(\mathrm{Pa}), \tau_{0}=$ yield stress $(\mathrm{Pa}), K=$ consistency index $\left(\mathrm{Pa} \cdot \mathrm{s}^{\mathrm{n}}\right), \mathrm{n}=$ flow behavior index (no units), and $\gamma=$ shear rate $\left(\mathrm{s}^{-1}\right)$.

A small-strain oscillation frequency sweep was also performed on yogurt samples at frequencies ranging from 0.01 to $100 \mathrm{~Hz}$. The applied deformation was $0.1 \%$ (determined by a strain sweep to be within the linear viscoelastic range). The elastic $\left(\mathrm{G}^{\prime}\right)$ and viscous $\left(\mathrm{G}^{\prime \prime}\right)$ moduli were recorded as a function of frequency, and the loss tangent, $\tan (\delta)$, was then calculated $(\tan \delta=$ $\left.\mathrm{G}^{\prime \prime} / \mathrm{G}^{\prime}\right)$.

All rheological measurements were done in duplicate after $1 \mathrm{~d}$, and $1,2,3$, and $4 \mathrm{wk}$ of storage at $5^{\circ} \mathrm{C}$.

\section{Statistical Analyses}

The $t$-test was used to test for differences among mean acidification times, WHC, and $\mathrm{pH}$ during storage using the SPSS software, with a level of significance at 0.05 . For analysis of rheological parameters, ANOVA was first carried out to determine the effects of yogurt production and storage time. Because the time variable did not significantly $(P>0.05)$ affect yield stress $\left(\tau_{0}\right)$, consistency index $(K)$, flow behavior index $(\mathrm{n})$, and both elastic $\left(\mathrm{G}^{\prime}\right)$ and viscous $\left(\mathrm{G}^{\prime \prime}\right)$ moduli, the $t$-test was used to test for differences among yogurt condition means over time at a level of significance at 0.05.

\section{RESULTS}

\section{Composition of EPS Bioingredients}

Two EPS powders were produced from the fermented whey medium containing $2.2 \pm 0.1 \mathrm{~g} / \mathrm{L}$ of EPS, $1.2 \pm 0.1$ 
Table 2. Composition of the crude and purified exopolysaccharide (EPS) powders (\% wt/wt). ${ }^{1}$

\begin{tabular}{lrlllll}
\hline Powder & \multicolumn{1}{c}{ EPS } & Lactose & Lactate & Acetate & Ash & Protein \\
\hline Crude powder & $2.0 \pm 0.1$ & $1.2 \pm 0.1$ & $61.6 \pm 0.2$ & $2.1 \pm 0.1$ & $25.0 \pm 0.1$ & $13.7 \pm 0.3$ \\
Purified powder & $17.4 \pm 0.3$ & $0.7 \pm 0.1$ & $28.3 \pm 0.3$ & $1.0 \pm 0.1$ & $14.7 \pm 0.2$ & $36.5 \pm 0.7$ \\
\hline
\end{tabular}

\footnotetext{
${ }^{1}$ Reported data are means and standard deviations for duplicate (EPS, lactose, lactate, and acetate) or quadruplicate (ash, protein) analyses.
}

$\mathrm{g} / \mathrm{L}$ of lactose, $67.7 \pm 0.2 \mathrm{~g} / \mathrm{L}$ of lactate, and $2.2 \pm 0.1 \mathrm{~g} / \mathrm{L}$ of acetate. The crude powder produced by direct freezedrying contained $2.0 \pm 0.1 \%$ of EPS and was mainly composed of lactate $(61.6 \pm 0.2 \%)$, ash $(25.0 \pm 0.1 \%)$, and proteins $(13.7 \pm 0.3 \%)$ (Table 2$)$. The partially purified powder produced by an ultrafiltration step contained higher amounts of EPS $(17.4 \pm 0.3 \%)$, and proteins (36.5 $\pm 0.7 \%)$ as well as lower concentrations of lactate (28.3 $\pm 0.3 \%)$ and ash $(14.7 \pm 0.2 \%)$ (Table 2$)$. No glucose or galactose was detected in the fermented whey medium and in the powders.

\section{Manufacture of Yogurts}

The effects of milk formulations (milk solid content and protein supplementation), and EPS concentration and powder type (crude or purified) added in milk before yogurt production on milk acidification time were studied (Table 1). The EPS-producing yogurt culture showed the highest acidification rate, with acidification times for $\mathrm{pH} 4.5$ of 301 and $331 \mathrm{~min}$ for $14.2 \%$ (D-14.2) and $13 \%$ (D-13) milks, respectively. The EPS-nonproducing yogurt culture exhibited acidification times of 405 and 374 min for $14.2 \%$ (V-14.2) and 13\% (V-13) milks (control yogurts), respectively. Adding purified EPS at 250 or $500 \mathrm{mg} / \mathrm{L}$ did not have a significant effect on acidification time for both 14.2 and $13 \%$ milks compared with control yogurts without added EPS (Table 1). However, adding crude EPS at $250 \mathrm{mg} / \mathrm{L}$ in the $14.2 \%$ milks (V250C-14.2) produced a significantly longer acidification time than for all other treatments.

\section{EPS Production in Yogurts}

The EPS content of yogurts produced with the EPSproducing yogurt culture determined weekly during the 4 -wk storage experiment was stable and averaged 341 \pm 33 and $288 \pm 127 \mathrm{mg} / \mathrm{L}$ for 14.2 (D-14.2) and 13\% (D13) milks, respectively. Yogurts produced with EPSnonproducing culture supplemented with $L b$. rhamnosus RW-9595M (V-LR-13) contained $185 \pm 62 \mathrm{mg} / \mathrm{L}$ of EPS after a 1-d storage period.

\section{Yogurt Analyses}

Yogurts were analyzed weekly for WHC, postacidification, and rheological characteristics during a 4-wk storage experiment at $5^{\circ} \mathrm{C}$.
WHC. The WHC of yogurts generally increased during storage at $5^{\circ} \mathrm{C}$, with the amount of excluded water measured after centrifugation decreasing from 50.2$57.5 \%$ of yogurt weight after $1 \mathrm{~d}$ to $43.7-55.0 \%$ after 4 wk (Table 3). However, $13 \%$ milk yogurts made with EPS-producing yogurt culture (D-13) and control yogurts (V-13) were more or less stable during the first 2 to $3 \mathrm{wk}$ of storage, with a late decrease of WHC between 3 and 4 wk (from 44.4 to $52.8 \%$ and 49.2 to $55.0 \%$, respectively). This WHC decrease was not observed for yogurts supplemented with EPS or made with $14.2 \%$ milk base. No significant effects of EPS addition and milk powder concentration were observed on WHC of yogurts.

Postacidification. Milk acidification was carried out for all yogurts until $\mathrm{pH} 4.5$. Then, they were rapidly cooled and stirred before storage at $5^{\circ} \mathrm{C}$. After $1 \mathrm{~d}$, the $\mathrm{pH}$ of yogurts ranged from 4.47 to 4.61 (Table 4). However, residual acidification activity was observed for all yogurts during the first 1 to $2 \mathrm{wk}$, with stable $\mathrm{pH}$ values ranging from 4.29 to 4.51 between 2 and $4 \mathrm{wk}$ of storage depending on conditions for yogurt production. Yogurt

Table 3. Water-holding capacity (WHC) of control and experimental yogurts measured by amounts of excluded aqueous phase (\% wt/wt) after centrifugation at $5000 \times \mathrm{g}$ for $10 \mathrm{~min}$ at $5^{\circ} \mathrm{C}$ as a function of storage time at $5^{\circ} \mathrm{C} .{ }^{1}$

\begin{tabular}{llllll}
\hline & \multicolumn{5}{c}{ Storage time $^{2}$} \\
\cline { 2 - 6 } Yogurts $^{2}$ & $1 \mathrm{~d}$ & $1 \mathrm{wk}$ & $2 \mathrm{wk}$ & $3 \mathrm{wk}$ & $4 \mathrm{wk}$ \\
\hline V-14.2 & $55.4^{\mathrm{a}}$ & $48.6^{\mathrm{b}}$ & $47.0^{\mathrm{c}}$ & $48.8^{\mathrm{b}}$ & $46.6^{\mathrm{c}}$ \\
V-125C-14.2 & $51.0^{\mathrm{a}}$ & $49.5^{\mathrm{ab}}$ & $49.0^{\mathrm{ab}}$ & $47.2^{\mathrm{b}}$ & $45.4^{\mathrm{c}}$ \\
V-125P-14.2 & $52.8^{\mathrm{a}}$ & $51.1^{\mathrm{b}}$ & $51.2^{\mathrm{abc}}$ & $49.0^{\mathrm{c}}$ & $48.7^{\mathrm{abc}}$ \\
V-250C-14.2 & $50.6^{\mathrm{abc}}$ & $54.3^{\mathrm{a}}$ & $50.0^{\mathrm{b}}$ & $48.9^{\mathrm{abc}}$ & $45.9^{\mathrm{c}}$ \\
V-250P-14.2 & $54.2^{\mathrm{a}}$ & $56.1^{\mathrm{a}}$ & $51.1^{\mathrm{b}}$ & $47.8^{\mathrm{c}}$ & $46.7^{\mathrm{c}}$ \\
V-500P-14.2 & $51.5^{\mathrm{a}}$ & $46.3^{\mathrm{b}}$ & $45.9^{\mathrm{b}}$ & $44.3^{\mathrm{c}}$ & $44.9^{\mathrm{c}}$ \\
V-500PF-14.2 & $53.7^{\mathrm{ab}}$ & $51.0^{\mathrm{bc}}$ & $52.9^{\mathrm{a}}$ & $47.5^{\mathrm{c}}$ & $47.7^{\mathrm{c}}$ \\
D-14.2 & $54.5^{\mathrm{a}}$ & $52.7^{\mathrm{ab}}$ & $50.2^{\mathrm{bc}}$ & $44.9^{\mathrm{cd}}$ & $43.7^{\mathrm{d}}$ \\
V-13 & $50.2^{\mathrm{b}}$ & $53.5^{\mathrm{ab}}$ & $52.3^{\mathrm{ab}}$ & $49.2^{\mathrm{ab}}$ & $55.0^{\mathrm{a}}$ \\
V-250P-13 & $56.5^{\mathrm{a}}$ & $56.6^{\mathrm{a}}$ & $48.3^{\mathrm{b}}$ & $48.2^{\mathrm{b}}$ & $48.3^{\mathrm{b}}$ \\
V-500P-13 & $57.5^{\mathrm{a}}$ & $52.5^{\mathrm{ab}}$ & $47.3^{\mathrm{c}}$ & $47.6^{\mathrm{bc}}$ & $46.5^{\mathrm{c}}$ \\
D-13 & $50.8^{\mathrm{b}}$ & $50.8^{\mathrm{b}}$ & $49.7^{\mathrm{b}}$ & $44.4^{\mathrm{c}}$ & $52.8^{\mathrm{a}}$ \\
\hline
\end{tabular}

a,b,c Means with the same letter (by rows) are not significantly different $(P>0.05)$.

${ }^{1}$ Reported data are means for duplicate yogurt productions and analyses.

${ }^{2}$ Yogurt treatments are identified by type of starter $(\mathrm{V}=$ Visbyvac B 500, D = DI-PROX TY 975), amount (in mg), and type of exopolysaccharide (EPS) powder ( $\mathrm{P}=$ purified powder, $\mathrm{C}=$ crude powder $)$ or corresponding EPS producer $(\mathrm{LR}=L b$. rhamnosus $)$, and last milk solid concentration level (13 or $14.2 \%)$. 
Table 4. Yogurt $\mathrm{pH}$ and change in $\mathrm{pH}$ during 4 -wk storage at $5^{\circ} \mathrm{C} .{ }^{1}$

\begin{tabular}{lllllll}
\hline & \multicolumn{5}{c}{ Storage time } \\
\cline { 2 - 5 } Yogurt $^{2}$ & $1 \mathrm{~d}$ & $1 \mathrm{wk}$ & $2 \mathrm{wk}$ & $3 \mathrm{wk}$ & $4 \mathrm{wk}$ & $\Delta \mathrm{pH}$ \\
\hline V-14.2 & $4.61^{\mathrm{a}}$ & $4.39^{\mathrm{b}}$ & $4.34^{\mathrm{b}}$ & $4.36^{\mathrm{b}}$ & $4.33^{\mathrm{b}}$ & $0.28^{\mathrm{A}}$ \\
V-125C-14.2 & $4.51^{\mathrm{a}}$ & $4.39^{\mathrm{b}}$ & $4.38^{\mathrm{b}}$ & $4.38^{\mathrm{b}}$ & $4.33^{\mathrm{b}}$ & $0.18^{\mathrm{AB}}$ \\
V-125P-14.2 & $4.51^{\mathrm{a}}$ & $4.34^{\mathrm{b}}$ & $4.35^{\mathrm{b}}$ & $4.35^{\mathrm{b}}$ & $4.32^{\mathrm{b}}$ & $0.19^{\mathrm{AB}}$ \\
V-250C-14.2 & $4.61^{\mathrm{a}}$ & $4.51^{\mathrm{b}}$ & $4.48^{\mathrm{b}}$ & $4.47^{\mathrm{b}}$ & $4.50^{\mathrm{b}}$ & $0.11^{\mathrm{B}}$ \\
V-250P-14.2 & $4.54^{\mathrm{a}}$ & $4.37^{\mathrm{b}}$ & $4.37^{\mathrm{b}}$ & $4.30^{\mathrm{c}}$ & $4.39^{\mathrm{b}}$ & $0.15^{\mathrm{AB}}$ \\
V-500P-14.2 & $4.57^{\mathrm{a}}$ & $4.41^{\mathrm{b}}$ & $4.34^{\mathrm{c}}$ & $4.32^{\mathrm{c}}$ & $4.34^{\mathrm{c}}$ & $0.23^{\mathrm{AB}}$ \\
V-500PF-14.2 & $4.61^{\mathrm{a}}$ & $4.51^{\mathrm{b}}$ & $4.36^{\mathrm{c}}$ & $4.37^{\mathrm{c}}$ & $4.36^{\mathrm{bc}}$ & $0.25^{\mathrm{AB}}$ \\
D-14.2 & $4.60^{\mathrm{a}}$ & $4.46^{\mathrm{b}}$ & $4.34^{\mathrm{cd}}$ & $4.38^{\mathrm{c}}$ & $4.35^{\mathrm{d}}$ & $0.25^{\mathrm{AB}}$ \\
V-13 & $4.56^{\mathrm{a}}$ & $4.39^{\mathrm{b}}$ & $4.29^{\mathrm{d}}$ & $4.33^{\mathrm{c}}$ & $4.33^{\mathrm{c}}$ & $0.23^{\mathrm{AB}}$ \\
V-250P-13 & $4.47^{\mathrm{a}}$ & $4.38^{\mathrm{ab}}$ & $4.36^{\mathrm{b}}$ & $4.31^{\mathrm{c}}$ & $4.33^{\mathrm{bc}}$ & $0.14^{\mathrm{AB}}$ \\
V-500P-13 & $4.50^{\mathrm{a}}$ & $4.43^{\mathrm{b}}$ & $4.39^{\mathrm{b}}$ & $4.37^{\mathrm{b}}$ & $4.38^{\mathrm{b}}$ & $0.12^{\mathrm{AB}}$ \\
D-13 & $4.55^{\mathrm{a}}$ & $4.39^{\mathrm{b}}$ & $4.33^{\mathrm{c}}$ & $4.38^{\mathrm{b}}$ & $4.37^{\mathrm{b}}$ & $0.18^{\mathrm{A}}$ \\
\hline
\end{tabular}

a,b,c Means with the same letter (by rows) are not significantly different $(P>0.05)$.

${ }_{\mathrm{A}, \mathrm{B}, \mathrm{C}}$ Differences between $\mathrm{pH}$ values measured after $1 \mathrm{~d}$ and $4 \mathrm{wk}$ of storage with the same letter (by column) are not significantly different $(P>0.05)$

${ }^{1}$ Reported data are means for duplicate yogurts.

${ }^{2}$ Yogurt treatments are identified by: type of starter $(\mathrm{V}=\mathrm{Visbyvac}$ B 500, D = DI-PROX TY 975), amount (in mg), and type of exopolysaccharide (EPS) powder $(\mathrm{P}=$ purified powder, $\mathrm{C}=$ crude powder $)$ or corresponding EPS producer $(\mathrm{LR}=L b$. rhamnosus $)$, and last milk solid concentration level (13 or $14.2 \%$ ).

made with $14.2 \%$ milk and $250 \mathrm{mg} / \mathrm{L}$ crude EPS (V250C-14.2) exhibited the highest $\mathrm{pH}$ (4.50) of all yogurt conditions after 4-wk storage (Table 4). However, no significant effects of EPS addition and milk powder concentration were observed on yogurt postacidification.

Rheological characteristics. To model the flow behavior of yogurts, the upward flow curves (shear stress) were fitted to the Herschel-Bulkley model to obtain the yield stress $\tau_{0}$, the consistency index $K$, and the flow behavior index $\mathrm{n}$. The effect of storage time for $4 \mathrm{wk}$ at $5^{\circ} \mathrm{C}$ on all rheological and viscoelastic parameters was not significant $(P>0.05)$, and mean values over time are reported (Table 5). Yield stress values obtained for all samples were low, ranging from 0.77 to $1.29 \mathrm{~Pa}$ (Table 5). For identical EPS addition and starter culture, the $14.2 \%$ yogurts showed higher yield stresses (1.15 and 1.20 Pa for V-250P-14.2 and V-500P-14.2, respectively) than those produced with $13 \%$ milk (1.01 and $0.99 \mathrm{~Pa}$ for $\mathrm{V}-250 \mathrm{P}-13$ and V-500P-13, respectively). The $14.2 \%$ control yogurts (V-14.2) showed the highest yield stress value $(1.29 \mathrm{~Pa})$, which was slightly but not significantly $(P>0.05)$ higher than yield stress of yogurts supplemented with purified EPS powder. Increasing the addition of purified EPS powder (125 to $500 \mathrm{mg} /$ L EPS) had no effect on the yield stress (1.17 for V125P-14.2 to 1.20 Pa for V-500P-14.2). However, yogurt supplementation with crude EPS caused a small but significant $(P<0.05)$ decrease in yield stress, with no effect of EPS concentration in the tested range (1.00 to
Table 5. Rheological parameters measured during flow and dynamic tests for yogurts made using different milk compositions, exopolysaccharide (EPS) supplementations, and starter cultures. ${ }^{1}$

\begin{tabular}{llllll}
\hline & \multicolumn{5}{c}{ Rheological property $^{2}$} \\
\cline { 2 - 6 } & $\begin{array}{l}\text { Yield } \\
\text { stress }\end{array}$ & $\begin{array}{l}\text { Consistency } \\
\text { index } K \\
\left(\mathrm{~Pa} \cdot \mathrm{s}^{\mathrm{n}}\right)\end{array}$ & $\begin{array}{l}\text { Flow } \\
\text { behavior } \\
\text { index n }\end{array}$ & $\mathrm{G}^{\prime}(\mathrm{Pa})$ & $\mathrm{G}^{\prime \prime}(\mathrm{Pa})$ \\
Yogurt $^{3}$ & $1.29^{\mathrm{a}}$ & $20.0^{\mathrm{b}}$ & $0.153^{\mathrm{b}}$ & $499^{\mathrm{a}}$ & $127^{\mathrm{a}}$ \\
\hline V-14.2 & $1.00^{\mathrm{cd}}$ & $21.2^{\mathrm{b}}$ & $0.221^{\mathrm{ab}}$ & $283^{\mathrm{cd}}$ & $71^{\mathrm{c}}$ \\
V-125C-14.2 & $1.17^{\mathrm{ab}}$ & $20.3^{\mathrm{b}}$ & $0.197^{\mathrm{ab}}$ & $392^{\mathrm{ab}}$ & $98^{\mathrm{b}}$ \\
V-125P-14.2 & $1.87^{\mathrm{d}}$ & $17.2^{\mathrm{c}}$ & $0.228^{\mathrm{a}}$ & $232^{\mathrm{d}}$ & $58^{\mathrm{d}}$ \\
V-250C-14.2 & $0.87^{\mathrm{b}}$ & $18.6^{\mathrm{bc}}$ & $0.227^{\mathrm{a}}$ & $382^{\mathrm{b}}$ & $96^{\mathrm{b}}$ \\
V-250P-14.2 & $1.15^{\mathrm{b}}$ & $19.7^{\mathrm{b}}$ & $0.229^{\mathrm{ab}}$ & $423^{\mathrm{ab}}$ & $105^{\mathrm{b}}$ \\
V-500P-14.2 & $1.20^{\mathrm{ab}}$ & $13.9^{\mathrm{d}}$ & $0.267^{\mathrm{a}}$ & $342^{\mathrm{bc}}$ & $86^{\mathrm{bc}}$ \\
V-500PF-14.2 & $1.08^{\mathrm{bc}}$ & $134^{\mathrm{ac}}$ & $0.254^{\mathrm{a}}$ & $311^{\mathrm{c}}$ & $78^{\mathrm{c}}$ \\
D-14.2 & $1.04^{\mathrm{bc}}$ & $30.2^{\mathrm{a}}$ & $0.215^{\mathrm{A}}$ & $301^{\mathrm{A}}$ & $75^{\mathrm{A}}$ \\
V-13 & $1.01^{\mathrm{A}}$ & $12.3^{\mathrm{C}}$ & $0.231^{\mathrm{A}}$ & $296^{\mathrm{A}}$ & $74^{\mathrm{A}}$ \\
V-250P-13 & $1.01^{\mathrm{A}}$ & $12.9^{\mathrm{BC}}$ & $0.258^{\mathrm{A}}$ & $288^{\mathrm{AB}}$ & $72^{\mathrm{A}}$ \\
V-500P-13 & $0.99^{\mathrm{A}}$ & $12.2^{\mathrm{BC}}$ & $0.278^{\mathrm{A}}$ & $246^{\mathrm{AB}}$ & $61^{\mathrm{A}}$ \\
D-13 & $0.90^{\mathrm{AB}}$ & $22.4^{\mathrm{A}}$ & $0.266^{\mathrm{A}}$ & $187^{\mathrm{B}}$ & $50^{\mathrm{A}}$ \\
V-LR-13 & $0.77^{\mathrm{B}}$ & $15.1^{\mathrm{B}}$ & 0.20 & &
\end{tabular}

a,b,c,A,B,C Means with the same letter (by columns) are not significantly different $(P>0.05)$; yogurts with 14.2 and $13 \%$ milk solids were analyzed separately (lowercase and uppercase letters, respectively).

${ }^{1}$ Reported values are means for duplicate yogurt productions and analyses after $1 \mathrm{~d}$, and $1,2,3$, and $4 \mathrm{wk}$ of storage at $5^{\circ} \mathrm{C}$, except for yogurt V-LR-13 that was stored only for $1 \mathrm{~d}$.

${ }^{2}$ Yield stress, consistency index, and flow behavior index were determined by fitting upward flow curves to the Herschel-Bulkley model; $\mathrm{G}^{\prime}$ and $\mathrm{G}^{\prime \prime}$ are the elastic and viscous moduli measured at $1 \mathrm{~Hz}$, respectively.

${ }^{3}$ Yogurt treatments are identified by type of starter $(\mathrm{V}=$ Visbyvac B 500, D = DI-PROX TY 975), amount (in mg), and type of EPS powder $(\mathrm{P}=$ purified powder, $\mathrm{C}=$ crude powder $)$ or corresponding EPS producer $(\mathrm{LR}=$ Lb. rhamnosus $)$, and last milk solid concentration level (13 or $14.2 \%)$

$0.87 \mathrm{~Pa}$ for V-125C-14.2 and V-250C-14.2, respectively). The lowest yield stress values were obtained for $13 \%$ milks fermented with the EPS yogurt culture, or by the non-EPS yogurt culture mixed with $L b$. rhamnosus RW9595M (0.90 and 0.77 Pa for D-13 and V-LR-13, respectively). Consistency coefficients for $14.2 \%$ yogurts were higher than for yogurts made of $13 \%$ milk (Table 5). Consistency coefficients from yogurts produced with the EPS yogurt culture were the highest for both milk compositions $\left(30.2\right.$ and $22.4 \mathrm{~Pa} \cdot \mathrm{s}^{\mathrm{n}}$ for $\mathrm{D}-14.2$ and D-13, respectively). The consistency coefficients of yogurts with added purified EPS (125 to $500 \mathrm{mg} / \mathrm{L}$ EPS) were not significantly different from those of control yogurts. In contrast, the addition of crude EPS at $250 \mathrm{mg} / \mathrm{L}$ resulted in significantly lower consistency coefficient values for $14.2 \%$ yogurts $\left(17.2\right.$ and $20.0 \mathrm{~Pa} \cdot \mathrm{s}^{\mathrm{n}}$ for $\mathrm{V}-250 \mathrm{C}-14.2$ and V-14.2, respectively) whereas no effect was observed at $125 \mathrm{mg} / \mathrm{L}$ EPS. The lowest $K$ value for $14.2 \%$ yogurts $\left(13.9 \mathrm{~Pa} \cdot \mathrm{s}^{\mathrm{n}}\right)$ was measured for yogurt V-500PF-14.2. Finally, the addition of $L b$. rhamnosus RW-9595M to the EPS-nonproducing starter culture gave yogurts with slightly but significantly higher $K$ values for $13 \%$ milk (15.1 Pa $\cdot \mathrm{s}^{\mathrm{n}}$ for V-LR-13 compared with $12.3 \mathrm{~Pa} \cdot \mathrm{s}^{\mathrm{n}}$ 


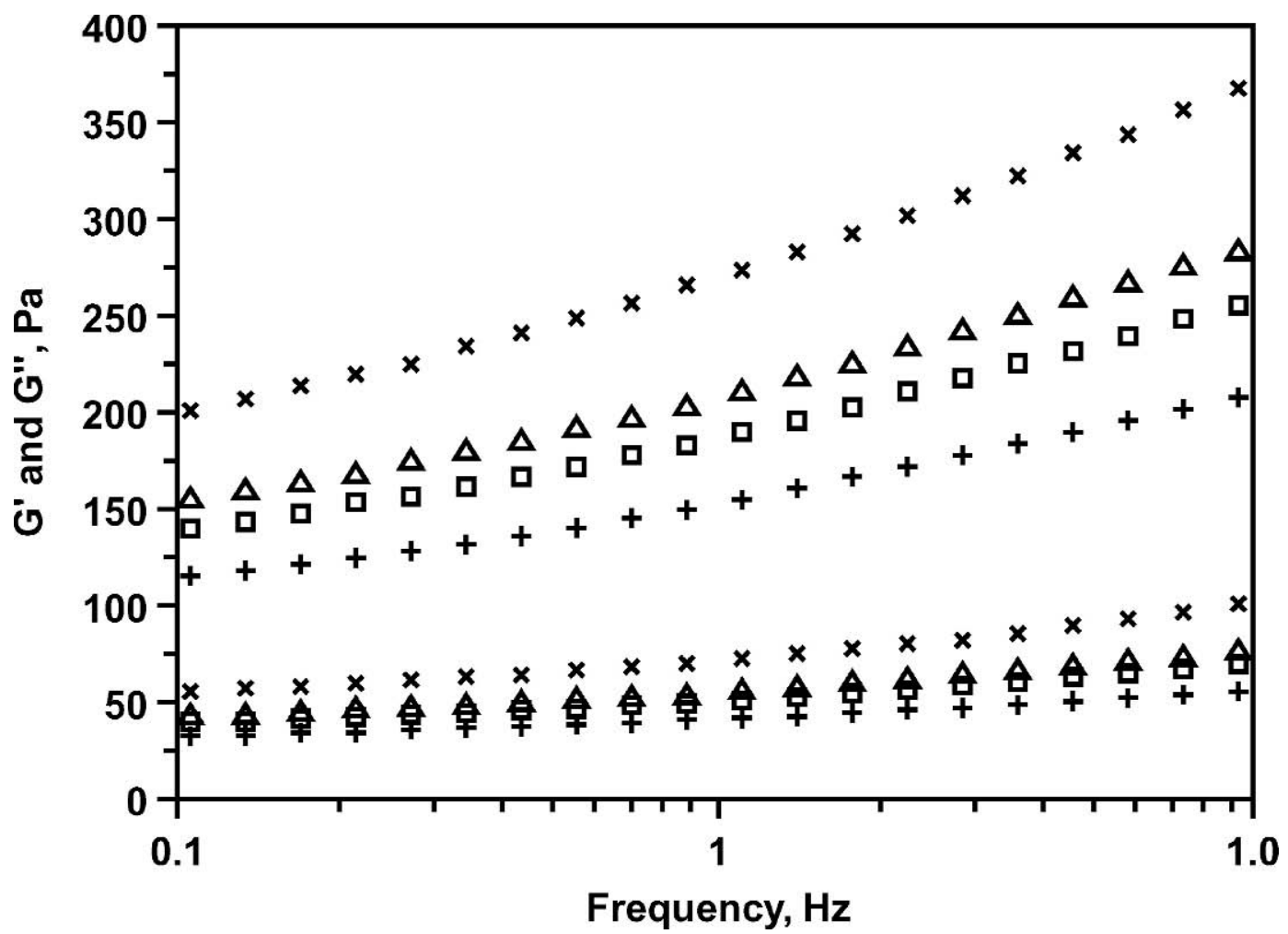

Figure 1. Small strain oscillation frequency sweeps of yogurts stored for $1 \mathrm{~d}$ at $5^{\circ} \mathrm{C}$. Measurements of the elastic modulus $\mathrm{G}^{\prime}$ (upper values) and viscous modulus $\mathrm{G}^{\prime \prime}$ (lower values) were carried out at $5^{\circ} \mathrm{C}$, and reported data are means for duplicate yogurts and analyses. $\times=\mathrm{V}-13 ; \Delta=\mathrm{V}-250 \mathrm{P}-13 ;+=\mathrm{D}-13 ; \square=\mathrm{V}-\mathrm{LR}-13$. Yogurt types are defined in Table 1.

for $\mathrm{V}-13)$. The flow behavior index $\mathrm{n}$ of $14.2 \%$ control yogurts (V-14.2) was lower than for all other $14.2 \%$ yogurt conditions, but this effect was significant $(P<$ 0.05 ) only for V-250C-14.2, V-250P-14.2, V-500PF-14.2, and $\mathrm{D}-14.2$, due to the relative high variability (Table 5 ). No change in $n$ values was observed when crude EPS concentration was increased from 125 to $250 \mathrm{mg} /$ L, or with purified EPS concentrations from 125 to 500 $\mathrm{mg} / \mathrm{L}$ in $14.2 \%$ milk. Moreover, the flow behavior index $\mathrm{n}$ of yogurts produced with the EPS-producing starter culture or with the EPS-nonproducing culture mixed with $L b$. rhamnosus RW-9595M were not significantly $(P>0.05)$ different from yogurts supplemented with EPS powders for the same milk concentration (Table 5). No significant effect of production conditions was observed on the flow behavior index $\mathrm{n}$ for $13 \%$ milk yogurts.

Small-amplitude shear stress oscillatory tests were carried out to study the evolution of gel texture during storage. Results of the frequency sweep reported as $G^{\prime}$ or $\mathrm{G}^{\prime \prime}$ vs. $\log$ (frequency) gave straight lines for all yogurts in the range of frequencies tested as illustrated in Figure 1. Table 5 shows the mean elastic and viscous moduli determined at $1 \mathrm{~Hz}$ for experimental yogurts during 4-wk storage. For the same starter culture and EPS supplementation level, $\mathrm{G}^{\prime}$ and $\mathrm{G}^{\prime \prime}$ values of yogurts produced with $14.2 \%$ milk were higher than for $13 \%$ milk. Values for $G^{\prime}$ and $G^{\prime \prime}$ were highest for control yogurts (499 and $127 \mathrm{~Pa}$ for V-14.2, respectively). Addition of purified EPS resulted in $14.2 \%$ milk yogurts with lower $\mathrm{G}^{\prime}$ and $\mathrm{G}^{\prime \prime}$ values $\left(P>0.05\right.$ for $\mathrm{G}^{\prime}$ and $P<$ 0.05 for $\left.G^{\prime \prime}\right)$, whereas no change was observed for $13 \%$ milk yogurts. Moreover, purified EPS concentration in the range from 125 to $500 \mathrm{mg} / \mathrm{L}$ did not significantly change $G^{\prime}$ and $G^{\prime \prime}$ values for both 13 and $14.2 \%$ milk yogurts. Addition of $250 \mathrm{mg} / \mathrm{L}$ crude EPS in $14.2 \%$ milk yogurts $(\mathrm{V}-250 \mathrm{C}-14.2)$ resulted in a significant $(P<0.05)$ decrease of both $\mathrm{G}^{\prime}$ and $\mathrm{G}^{\prime \prime}$. Addition of $500 \mathrm{mg} / \mathrm{L}$ purified EPS after yogurt fermentation (V-500PF-14.2) gave nonsignificantly $(P>0.05)$ lower $G^{\prime}$ and $G^{\prime \prime}$ values compared with the same addition in milk but significantly $(P<0.05)$ lower values than for control yogurt $(\mathrm{V}-14.2)$. For $14.2 \%$ milks, the use of an EPS yogurt starter culture (D-14.2) also gave lower $\mathrm{G}^{\prime}$ and $\mathrm{G}^{\prime \prime}$ values compared with the control yogurt (V-14.2). Finally, the addition of $L b$. rhamnosus RW-9595M to the non-EPS yogurt culture (V-LR-13) resulted in the lowest $G^{\prime}$ and $G^{\prime \prime}$ values. The use of different milk bases, EPS supplementa- 
tions, and starter cultures did not show a significant effect on the $\mathrm{G}^{\prime \prime} / \mathrm{G}^{\prime}$ ratio, because identical loss tangent values were obtained for all yogurts, averaging 0.271 \pm 0.005 after 1 -d storage. However, a decrease of the mean loss tangent for all yogurts was observed during storage at $5^{\circ} \mathrm{C}(0.253 \pm 0.002,0.247 \pm 0.002,0.245 \pm$ 0.003 , and $0.244 \pm 0.002$, after $1,2,3$, and $4 \mathrm{wk}$, respectively).

\section{DISCUSSION}

In the last decade, many studies have been focused on yogurt texture and stability because of increasing consumer demand for stirred yogurts with a smooth and creamy texture. Well-known parameters for texture improvement include the use of an increased content of milk solids such as fat, proteins, or sugars, the selection of starter culture and process conditions, as well as the addition of stabilizers such as pectin, starch, alginate, and gelatine (Sodini et al., 2004). However, considering requests for low-calorie yogurts containing minimal amounts of food additives, the use of naturally EPS-producing lactic acid bacteria as yogurt starter cultures has recently emerged on the market. Ropiness is a characteristic of yogurts generally related to EPSproducing cultures whereas firmness and elasticity are likely to be influenced more by the protein matrix of the yogurt (Rawson and Marshall, 1997). Until now and despite their GRAS (generally regarded as safe) status, EPS from lactic acid bacteria have not been exploited as food additives but produced directly during yogurt manufacture by selected strains, mainly because of low production levels (De Vuyst and Degeest, 1999a). In this study, EPS from $L b$. rhamnosus RW-9595M produced in situ or added as bioingredient were compared for their functional properties in yogurt.

A high level of EPS production $(2.2 \pm 0.1 \mathrm{~g} / \mathrm{L})$ was obtained during batch culture of $L b$. rhamnosus RW$9595 \mathrm{M}$ in a supplemented whey medium containing $11 \%$ whey solids, $1 \%$ yeast extract, and some minerals. This is in agreement with Bergmaier et al. (2001) who reported production levels of 1.7 and $2.3 \mathrm{~g} / \mathrm{L}$ of EPS in the same medium basis, but with 5 or $8 \%$ whey permeate powder, respectively. The EPS produced by $L b$. rhamnosus RW-9595M are composed of heptasaccharide repeated units of rhamnose, glucose, galactose, and pyruvate in a proportion of $4: 2: 1: 1$, and were claimed to present interesting properties for stabilizing acidified milk products because of low charge density, namely 1 charge per 7 residues (Van Calsteren et al., 2002).

In our study, EPS bioingredients were obtained with 2 different purities: a crude powder obtained by directly freeze-drying the whole fermented whey-based medium and containing $2.0 \pm 0.1 \% \mathrm{EPS}$; and a purified powder with an EPS content of $17.4 \pm 0.3 \%$ obtained by ultrafiltering the fermented medium before freeze-drying. The powders were added to milk at different concentrations to study the effects of EPS addition up to $500 \mathrm{mg} / \mathrm{L}$ on yogurt characteristics; these experimental yogurts were compared with yogurts produced with EPS-producing starter cultures. Yogurts produced with 14.2\% milk and the EPS-nonproducing culture supplemented with purified powder (EPS concentration ranging from 0 to $500 \mathrm{mg} / \mathrm{L}$ ) had acidification times of 6.5 to $7 \mathrm{~h}$, showing no effect of purified EPS powder supplementation. However, the acidification rate of milks supplemented with crude powder was approximately $1 \mathrm{~h}$ longer. This effect was probably caused by the high amount of crude powder that was added to reach EPS concentrations of 125 and $250 \mathrm{mg} / \mathrm{L}(6.3$ and $12.6 \mathrm{~g} /$ $\mathrm{L}$, respectively). This high addition of crude powder containing a high concentration of lactate $(61.6 \pm 0.2 \%)$ increased the buffering capacity of the milk base and may have inhibited the starter culture. Our data show that even for the very high EPS production measured in this study, EPS need to be partially purified for use in yogurt so that the acidification rate is not affected.

Exopolysaccharide-producing strains have been successfully used to decrease fermented milk susceptibility to syneresis (Toba et al., 1990; Wacher-Rodarte et al., 1993; Hassan et al., 1996). The shear-induced microstructure in yogurt made with EPS-producing culture was shown to consist of compartmentalized protein aggregates between channels containing EPS, which hinders syneresis as well as the buildup of structure after stirring (Hassan et al., 2003). However, Duggan and Waghorne (2003) did not observe a significant effect of EPS-producing ropy culture on yogurt syneresis compared with a classical yogurt culture. Additionally, they found that all rheological parameters were less reproducible for the EPS-producing culture, which could also explain the high variations in WHC observed in our study (Table 3).

Several studies reported that increasing the milk concentration resulted in higher WHC (Sodini et al., 2004) as observed in our study for 13\% (V13) and $14.2 \%$ (V14.2) milk yogurts. However, higher total milk solids did not significantly increase the WHC of yogurts produced using EPS-producing starter cultures (Table 3), in agreement with Wacher-Rodarte et al. (1993). In this case, EPS probably acted as stabilizing agent making the effect of milk concentration less significant. Nevertheless, WHC generally increased during storage, indicating that protein rearrangement occurred during storage at refrigerated temperature (Ozer et al., 1998).

No effect of EPS on yogurt postacidification during storage was expected, because low amounts of EPS up to $500 \mathrm{mg} / \mathrm{L}$ do not significantly affect the buffering 
capacity of yogurt and are not expected to modify residual bacterial activity. All control and experimental yogurts exhibited similar postacidification activity with $\mathrm{pH}$ after 4 -wk storage in the range 4.33 to 4.39 (Table 4). The only exception was for yogurt with crude EPS powder at the highest concentration of $250 \mathrm{mg} / \mathrm{L}$ (V250C-14.2), which showed little postacidification and high $\mathrm{pH}$ after 4-wk storage. This data, as for longer acidification times for this treatment, could be due to high buffering capacity of the crude EPS powder and starter culture inhibiting levels of lactic acid in yogurt.

Flow and dynamic rheological tests were carried out to gain more information on yogurt texture. Shear stress measurements by applying increasing and decreasing shear rates on yogurts showed a hysteresis loop, which demonstrates the thixotropic flow behavior of non-Newtonian shear-thinning fluids such as yogurt (Koksoy and Kilic, 2003). Yogurts with no EPS showed slightly higher shear stress values than yogurts containing EPS added as bioingredients or produced in situ (Table 5). This was also reported by Hassan et al. (2003) for genetic variants of Streptococcus thermophilus that differed only in ability or inability to produce EPS. The authors tentatively explained the lower yield stress values of EPS-containing yogurts by a decreased possibility of interactions between the protein aggregates during flow (Hassan et al., 2003). Skriver et al. (1993) also reported lower yield stress for yogurt made of whole milk fermented by an experimental ropy culture compared with the nonropy culture YC-180.

Many reports indicate that the use of EPS-producing starter cultures in yogurt fermentation results in a product with increased viscosity at relatively high shear rates ( $>10 \mathrm{~s}^{-1}$; Hess et al., 1997). This was also observed in our study where consistency indexes and apparent viscosities were higher for yogurts made with the EPSproducing culture (D-14.2 and D-13) than those with the nonproducing one (V-14.2 and V-13). Using confocal laser scanning microscopy, Hassan et al. (2003) showed that yogurts made with EPS-producing cultures contained large pores associated with the presence of EPS and a protein network made up of thick strands consisting of densely aggregated protein particles. The presence of EPS channels in the serum would thus confer a more polymer-like rheological behavior to the continuous phase resulting in increased consistency index and viscosity of the yogurt (Hassan et al., 2003).

In a study to evaluate the effects of different EPSproducing starter cultures and commercial stabilizers on rheological properties of stirred-style nonfat yogurts, EPS produced in situ and their interactions with bacterial cells and milk proteins gave yogurts with rheological properties that were different from those containing commercial stabilizers (Hess et al., 1997). The present study is the first to report the incorporation of EPS as bioingredient in yogurt. The addition of EPS for concentrations up to $500 \mathrm{mg} / \mathrm{L}$ gave lower yogurt consistency indexes and viscosities compared with yogurts produced with EPS-producing cultures, and appeared to be ineffective at increasing these parameters. Several authors have already reported that Lactobacillus strains produce different types of EPS, which also depend on culture conditions for some strains (Grobben et al., 1996; De Vuyst and Degeest, 1999b). Equal amounts of EPS with different structures or molecular weights will also differ in their effects on the viscosity of stirred yogurts due to differences in polysaccharide intrinsic viscosity (Faber et al., 1998). Therefore, EPS from different EPS-producing strains have different viscosifying effects in yogurt (Sebastiani and Zelger, 1998), and it is difficult to compare rheological data from yogurts supplemented with EPS bioingredient to those of yogurts manufactured with a culture producing a different type of EPS.

For more accurate comparison and assessment of the effects of the mode of EPS incorporation on rheological characteristics of the final product, yogurts supplemented with purified EPS powder from $L b$. rhamnosus RW-9595M were compared with yogurts produced with the non EPS-producing yogurt culture mixed with an active culture of $L b$. rhamnosus RW-9595M. This mixed starter culture allowed the production of $185 \pm 62 \mathrm{mg} /$ $\mathrm{L}$ of EPS in yogurts, which led to slightly higher consistency index than for $13 \%$ milk control yogurts $(P<0.05)$ or 13\% milk yogurts supplemented with EPS $(P>0.05)$, but still very low compared with $13 \%$ yogurts made with the EPS-producing yogurt culture that contained $288 \pm 127 \mathrm{mg} / \mathrm{L}$ of EPS. These results show the low apparent effectiveness of EPS from $L b$. rhamnosus RW$9595 \mathrm{M}$ to improve yogurt texture. Moreover, EPS macromolecules added to milk before fermentation can interfere with acid coagulation and gel network formation differently than EPS produced in situ during milk acidification.

Small-amplitude shear stress oscillatory testing was used to analyze the viscoelastic properties of yogurts: the elastic $\left(\mathrm{G}^{\prime}\right)$ and viscous moduli $\left(\mathrm{G}^{\prime \prime}\right)$. The $\mathrm{G}^{\prime}$ and $\mathrm{G}^{\prime \prime}$ values for yogurt produced with EPS yogurt cultures were lower than for control yogurts without EPS, as already observed for ropy cultures enhancing the viscosity of yogurts but producing a weaker gel (Hess et al., 1997; Rawson and Marshall, 1997; Hassan et al., 2001, 2003). Ozer et al. (1998) observed that protein rearrangement continued to occur throughout the storage period and more protein-protein contacts were established. In our study, even though both $\mathrm{G}^{\prime}$ and $\mathrm{G}^{\prime \prime}$ values did not significantly vary during 4 -wk storage of yogurts at refrigerated temperature, loss tangent values sig- 
nificantly decreased for all yogurts, confirming the rearrangement of yogurt structure during storage to a more solid-like gel.

Milk supplementation with EPS did not apparently have the same effect on $G^{\prime}$ and $G^{\prime \prime}$ of yogurt compared with EPS produced in situ by EPS-producing starter cultures. The EPS addition resulted in low $\mathrm{G}^{\prime}$ and $\mathrm{G}^{\prime \prime}$ values, but with no effect of EPS concentration. No clear relationship between yogurt viscosity and EPS concentration has been previously reported, which has led to the assumption that the amount of EPS may be less important for the rheological properties of the product than the type of EPS and interactions of the polymer with milk proteins (van Marle and Zoon, 1995; Faber et al., 1998; Sebastiani and Zelger, 1998; Marshall and Rawson, 1999; Shihata and Shah, 2002). The intrinsic viscosity of EPS depends on molecular mass and chain stiffness, with no clear effect of the chemical composition of polysaccharides. However, $\beta(1-4)$ linkages in the backbone lead to stiffer chains than do $\beta(1-$ 2), $\beta(1-3)$, or $\alpha$ linkages (Laws and Marshall, 2001). For a given EPS concentration, the viscosity of stirred fermented milks was strongly related to intrinsic viscosity of EPS produced by the studied strains (RuasMadiedo et al., 2002b). The low viscosifying properties of EPS from $L b$. rhamnosus RW-9595M are thus probably because the polysaccharide chain backbone contain only $\beta(1-3)$ or $\alpha$ linkages with only one side group per repeated unit (Van Calsteren et al., 2002). In contrast, the high thickening EPS from Lactococcus lactis ssp. cremoris NIZO B40 contains a repeated unit of $3 \beta(1-$ 4)-linked monosaccharides with 2 side groups (Tuinier et al., 1999b).

The in situ production of EPS by Lb. rhamnosus RW$9595 \mathrm{M}$ combined with the non-EPS starter culture (185 $\pm 62 \mathrm{mg} / \mathrm{L})$ resulted in yogurts with lower $\mathrm{G}^{\prime}(P<0.05)$ and $\mathrm{G}^{\prime \prime}(P>0.05)$ values compared with $13 \%$ milk control yogurts and yogurts supplemented with $250 \mathrm{mg} / \mathrm{L}$ of EPS. These data indicate a more pronounced effect of EPS produced in situ on yogurt rheological characteristics, as shown above for yield stress and consistency index. Finally, yogurts supplemented with EPS bioingredient after milk acidification exhibited very low consistency and high flow behavior indexes. This data can be explained in part by the difficulty in redispersing and solubilizing the EPS powder in yogurt, as confirmed by visual heterogeneity. In addition, different interactions may occur between EPS, proteins, and yogurt protein aggregates when EPS is added to milk before fermentation, produced in situ by the culture, or added after the protein gel network is formed.

\section{CONCLUSIONS}

This study showed that EPS from $L b$. rhamnosus RW-9595M added to milk as bioingredient had different effects on rheological properties of the final yogurt compared with EPS produced in situ by the EPS-producing culture. The addition of EPS up to $500 \mathrm{mg} / \mathrm{L}$ or the use of EPS-producing cultures resulted in yogurts with lower yield stress values and viscoelastic moduli compared with yogurts without EPS, with no apparent effect of EPS concentration. However, the consistency index was higher for yogurts produced with the EPSproducing culture, and to a lesser extent with the mixed culture containing $L b$. rhamnosus RW-9595M, compared with yogurts supplemented with EPS powders. Finally, the concentration of EPS in yogurt may be less important for rheological properties of the product than the type of EPS and interactions of the polymer with milk proteins. Consequently, in situ EPS production by the lactic starter seems to be a better approach than adding EPS as bioingredient to improve rheological characteristics of yogurt. Moreover, there is still a need for structure/function studies for optimal EPS selection and use in yogurt.

\section{ACKNOWLEDGMENTS}

This work was supported by Emmi AG (Emmen, Switzerland). The authors thank Gilles Jéquier and Albin Dübach from Emmi AG for fruitful discussions. Peter Fischer from the Laboratory of Food Process Engineering at ETH is acknowledged for valuable advices and access to the rheometer.

\section{REFERENCES}

AOAC. 1990. Official Methods of Analysis. 15th ed. Association of Official Analytical Chemists, Arlington, VA.

Bergmaier, D., C. P. Champagne, and C. Lacroix. 2003. Exopolysaccharide production during batch cultures with free and immobilized Lactobacillus rhamnosus RW-9595M. J. Appl. Microbiol. 95:1049-1057.

Bergmaier, D., C. Lacroix, M. G. Macedo, and C. P. Champagne. 2001. New method for exopolysaccharide determination in culture broth using stirred ultrafiltration cells. Appl. Microbiol. Biotechnol. 57:401-406.

Cayot, P., J. F. Fairise, B. Colas, D. Lorient, and G. Brule. 2003. Improvement of rheological properties of firm acid gels by skim milk heating is conserved after stirring. J. Dairy Res. 70:423-431.

Cerning, J. 1995. Production of exopolysaccharides by lactic acid bacteria and dairy propionibacteria. Lait 75:463-472.

Chabot, S., H. L. Yu, L. De Léséleuc, D. Cloutier, M. R. Van Calsteren, M. Lessard, D. Roy, M. Lacroix, and D. Oth. 2001. Exoploysaccharides from Lactobacillus rhamnosus RW-9595M stimulate TNF, IL-6 and IL-12 in human and mouse cultures immunocompetent cells, and IFN- $\gamma$ in mouse splenocytes. Lait 81:683-697.

de Man, J. C., M. Rogosa, and M. E. Sharpe. 1960. A medium for the cultivation of lactobacilli. J. Appl. Bacteriol. 23:130-135.

De Vuyst, L., and B. Degeest. 1999a. Exopolysaccharides from lactic acid bacteria: Technological bottlenecks and practical solutions. Macromol. Symp. 140:31-41.

De Vuyst, L., and B. Degeest. 1999b. Heteropolysaccharides from lactic acid bacteria. FEMS Microbiol. Rev. 23:153-177.

Duboc, P., and B. Mollet. 2001. Applications of exopolysaccharides in the dairy industry. Int. Dairy J. 11:759-768. 
Dubois, M., K. A. Gilles, J. K. Hamilton, P. A. Rebers, and F. Smith. 1956. Colorimetric method for determination of sugars and related substances. Anal. Chem. 28:350-356.

Duggan, E., and E. Waghorne. 2003. Long-term evaluation of production protocols for stirred yogurts produced using two different cultures. Milchwissenschaft 58:52-55.

Dupont, I., D. Roy, and G. Lapointe. 2000. Comparison of exopolysaccharide production by strains of Lactobacillus rhamnosus and Lactobacillus paracasei grown in chemically defined medium and milk. J. Ind. Microbiol. Biotechnol. 24:251-255.

Faber, E. J., P. Zoon, J. P. Kamerling, and J. F. G. Vliegenthart. 1998. The exopolysaccharides produced by Streptococcus thermophilus Rs and Sts have the same repeating unit but differ in viscosity of their milk cultures. Carbohydr. Res. 310:269-276.

Grobben, G. J., M. R. Smith, J. Sikkema, and J. A. M. de Bont. 1996. Influence of fructose and glucose on the production of exopolysaccharides and the activities of enzymes involved in the sugar metabolism and the synthesis of sugar nucleotides in Lactobacillus delbrueckii subsp. bulgaricus NCFB 2772. Appl. Microbiol. Biotechnol. 46:279-284.

Hassan, A. N., M. Corredig, and J. F. Frank. 2001. Viscoelastic properties of yogurt made with ropy and non-ropy exopolysaccharides producing cultures. Milchwissenschaft 56:684-687.

Hassan, A. N., J. F. Frank, K. A. Schmidt, and S. I. Shalab. 1996. Textural properties of yogurt made with encapsulated nonropy lactic cultures. J. Dairy Sci. 79:2098-2103.

Hassan, A. N., R. Ipsen, T. Janzen, and K. B. Qvist. 2003. Microstructure and rheology of yogurt made with cultures differing only in their ability to produce exopolysaccharides. J. Dairy Sci. 86:1632-1638.

Hess, S. J., R. F. Roberts, and G. R. Ziegler. 1997. Rheological properties of nonfat yogurt stabilized using Lactobacillus delbrueckii ssp. bulgaricus producing exopolysaccharide or using commercial stabilizer systems. J. Dairy Sci. 80:252-263.

Kleerebezem, M., R. van Kranenburg, R. Tuinier, I. C. Boels, P. Zoon, E. Looijesteijn, J. Hugenholtz, and W. M. de Vos. 1999. Exopolysaccharides produced by Lactococcus lactis: from genetic engineering to improved rheological properties? Antonie Van Leeuwenhoek 76:357-365.

Koksoy, A., and M. Kilic. 2003. Effects of water and salt level on rheological properties of ayran, a Turkish yogurt drink. Int. Dairy J. 13:835-839.

Laws, A. P., and V. M. Marshall. 2001. The relevance of exopolysaccharides to the rheological properties in milk fermented with ropy strains of lactic acid bacteria. Int. Dairy J. 11:709-721.

Macedo, M. G., C. Lacroix, N. Gardner, and C. P. Champagne. 2002. Effect of medium supplementation on exopolysaccharide production by Lactobacillus rhamnosus RW-9595M in whey permeate base medium. Int. Dairy J. 12:419-426.

Marshall, V. M., and H. L. Rawson. 1999. Effects of exopolysaccharide-producing strains of thermophilic lactic acid bacteria on the texture of stirred yogurt. Int. J. Food Sci. Technol. 34:137-143.
Ozer, B. H., R. K. Robinson, A. S. Grandison, and A. E. Bell. 1998. Gelation properties of milk concentrated by different techniques. Int. Dairy J. 8:793-799.

Rawson, H. L., and V. M. Marshall. 1997. Effect of ropy strain of Lactobacillus delbrueckii ssp. bulgaricus and Streptococcus thermophilus on rheology of stirred yogurt. Int. J. Food Sci. Technol. 32:213-220.

Ruas-Madiedo, P., J. Hugenholtz, and P. Zoon. 2002a. An overview of the functionality of exopolysaccharides produced by lactic acid bacteria. Int. Dairy J. 12:163-171.

Ruas-Madiedo, P., R. Tuinier, M. Kanning, and P. Zoon. 2002b. Role of exopolysaccharides produced by Lactococcus lactis subsp. cremoris on the viscosity of fermented milks. Int. Dairy J. 12:689-695.

Sebastiani, H., and G. Zelger. 1998. Texture formation by thermophilic lactic acid bacteria. Milchwissenschaft 53:15-20.

Shihata, A., and N. P. Shah. 2002. Influence of addition of proteolytic strains of Lactobacillus delbrueckii subsp. bulgaricus to commercial ABT starter cultures on texture of yogurt, exopolysaccharide production and survival of bacteria. Int. Dairy J. 12:765-772.

Skriver, A., H. Roemer, and K. B. Qvist. 1993. Rheological characterization of stirred yogurt: Viscosimetry. J. Texture Stud. 24:185-198.

Sodini, I., F. Remeuf, S. Haddad, and G. Corrieu. 2004. The relative effect of milk base, starter, and process on yogurt texture: A review. Crit. Rev. Food Sci. Nutr. 44:113-137.

Sutherland, I. W. 1972. Bacterial exopolysaccharides. Adv. Microb. Physiol. 8:143-213.

Toba, T., H. Nakajima, A. Tobitani, and S. Adachi. 1990. Scanning electron microscopic and texture studies on characteristic consistency of Nordic ropy sour milk. Int. J. Food Microbiol. 11:313-320.

Tuinier, R., J. K. G. Dhont, and C. G. de Kruif. 2000. Depletioninduced phase separation of aggregated protein colloids by an exocellular polysaccharide. Langmuir 16:1479-1507.

Tuinier, R., E. ten Grotenhuis, C. Holt, P. A. Timmins, and C. G. de Kruif. 1999a. Depletion interaction of casein micelles and an exocellular polysaccharide. Phys. Rev. E 60:848-856.

Tuinier, R., P. Zoon, C. Olieman, M. A. Cohen Stuart, G. J. Fleer, and C. G. de Kruif. 1999b. Isolation and physical characterization of an exocellular polysaccharide. Biopolymers 49:1-9.

Van Calsteren, M. R., C. Pau-Roblot, A. Bégin, and D. Roy. 2002. Structure determination of the exopolysaccharide produced by Lactobacillus rhamnosus strains RW-9595M and R. Biochem. J. 363:7-17.

van Marle, M. E., and P. Zoon. 1995. Permeability and rheological properties of microbially and chemically acidified skim-milk gels. Neth. Milk Dairy J. 49:47-65.

Wacher-Rodarte, C., M. V. Galvin, A. Farres, F. Gallardo, V. M. E. Marshall, and M. Garcia-Garibay. 1993. Yogurt production from reconstituted skim milk powders using different polymer and non-polymer forming starter cultures. J. Dairy Res. 60:247-254. 